\title{
¿ES POSIBLE APLICAR EN CHILE EL REMEDIO RESOLUTORIO FRENTE AL INCUMPLIMIENTO PREVISIBLE DEL CONTRATO A LA LUZ DEL ORDENAMIENTO JURÍDICO ACTUAL?
}

\author{
IS IT POSSIBLE TO APPLY IN CHILE THE RESOLUTIONARY \\ REMEDY FOR THE FORESEEABLE BREACH OF THE \\ CONTRACT IN THE CURRENT LEGAL SYSTEM?
}

CAMILA ALARCÓN IRELAND*

\section{Resumen}

La presente investigación dogmática, tiene por objeto determinar si es que es posible aplicar en Chile la doctrina de la resolución por incumplimiento anticipado del contrato en el contexto de obligaciones sujetas a plazo en las cuales el acreedor, previo al vencimiento del mismo, ha tomado conocimiento fehaciente de que el deudor no cumplirá con su cometido en tiempo y forma. Lo anterior, enfocado principalmente a evitar un perjuicio patrimonial mayor y a contar con la posibilidad de desvincularse anticipadamente del contrato a fin de vincularse a otra relación contractual que permita satisfacer idóneamente sus intereses. Para lo anterior se realizará un análisis de la normativa interna actualmente vigente, a la luz de los criterios que nos proporciona el derecho uniforme.

Artículo recibido para su evaluación el 5 de noviembre de 2021, y aprobado para su publicación el 13 de diciembre de 2021.

* Abogada. Magíster en Derecho Privado por la Universidad de Valparaíso, Chile. E-mail: alarcon.ireland@gmail.com. 


\title{
Palabras Clave
}

Obligaciones sujetas a plazo; incumplimiento contractual; remedio resolutorio; resolución por incumplimiento anticipado; derecho uniforme.

\begin{abstract}
The purpose of this research is to determine whether it is possible to apply in Chile the doctrine of anticipatory breach of contract in the context of obligations subject to a term when the creditor, prior to the expiration of the contract, indubitably know that the debtor will not fulfill his obligations in a timely manner. Mainly focused on avoiding a greater patrimonial damage and have the possibility to leave the contract in with the aim to celebrate another contract which adequately satisfy the interests of the creditor, analyzing. The national current regulations, in light of the criteria provided by the uniform law.
\end{abstract}

\section{Keywords}

Obligations subject to term; breach of contract; remedy for resolution; anticipatory breach; - uniform law.

\section{INTRODUCCIÓN.}

En la presente investigación, nos encontramos en el supuesto en que existe un contrato vigente entre ambas partes conforme al cual, sus obligaciones o una de ellas se encuentra sujeta a plazo y antes de la llegada del mismo, el acreedor toma conocimiento en forma fehaciente y en virtud de hechos objetivos, de que el deudor no dará cumplimiento a su cometido una vez vencido el plazo. Conforme a la normativa actual de nuestro ordenamiento jurídico interno, no existe norma expresa que permita al acreedor de aquella obligación sujeta a plazo, desligarse de este contrato, a pesar de que su incumplimiento en tiempo y forma es inminente. El objeto del presente trabajo consiste en determinar si, de conformidad al ordenamiento jurídico nacional, la doctrina de la resolución por incumplimiento anticipado es susceptible de ser aceptada en nuestro país, de manera tal, que sin necesidad de tener que esperar que el contrato sea exigible, el acreedor pueda optar a la resolución del mismo para efectos de garantizar sus intereses, en la medida en que este incumplimiento sea previsible y 
comprobable fehacientemente. Su importancia radica principalmente en que atendida la naturaleza fungible de las obligaciones predominantes en el tráfico jurídico actual y el carácter utilitario del contrato, en orden a que es un instrumento concebido para la satisfacción de los intereses de las partes contratantes, es que no es provechoso mantener vinculadas jurídicamente a las partes a un contrato que no cumple con su finalidad y que no reporta a ninguna de ellas, beneficio económico alguno. La resolución en cuanto mecanismo de protección del acreedor tiene una operación simple, toda vez que permite que el acreedor se desvincule del contrato que ya no le resulta útil, quedando sin efecto la relación contractual, liberando al acreedor de cumplir por su parte la obligación. Por tanto es altamente probable, dependiendo del caso en concreto, que sea mucho más conveniente a los intereses de las partes, desvincularse del contrato para poder rápidamente celebrar una operación de reemplazo. Si el acreedor logra acreditar que su deudor ha incurrido en un incumplimiento anticipado de la obligación, toda vez que en virtud de hechos objetivos, toma conocimiento de que la misma no se va a cumplir, podría ejercer la acción de resolución del contrato antes de que el plazo se venza permitiéndole reducir significativamente una serie de perjuicios económicos que le generaría el hecho de esperar a que el plazo se cumpla para que se configure el incumplimiento, y recién en ese momento demandar la resolución.

\section{PLANTEAMIENTO DEL PROBLEMA.}

Por regla general, en los casos en que una obligación está sujeta a un plazo para su cumplimiento, suponen en principio, que el deudor no está obligado a cumplir antes de la llegada del mismo. Nos situamos en aquella situación en que la obligación existe, sin embargo, no es exigible mientras se encuentre pendiente el plazo. Sin perjuicio de aquello, el deudor podría renunciar a dicho plazo, en la medida en que únicamente éste haya sido establecido en su exclusivo beneficio individual, según se desprende de los artículos 12 y 1497 del Código Civil. Por tanto, el plazo, es el momento que distingue la obligación existente y no exigible, con la obligación incumplida, en caso de que el deudor lo haya dejado pasar y no haya ejecutado su cometido.

Según se desprende de la regulación del Código Civil, el plazo produce tres consecuencias:

a. La obligación se hace exigible. 
b. Si no se cumple con la obligación hasta su llegada, se configura el incumplimiento.

c. El deudor se constituye en mora.

Considerando lo anterior, para efectos de la siguiente investigación, nos situaremos en el supuesto en que habiendo celebrado las partes un contrato en virtud del cual sus obligaciones o una de ellas se encuentra sujeta a plazo y antes de la llegada del mismo, el acreedor toma conocimiento en forma fehaciente y en virtud de hechos objetivos, de que el deudor no dará cumplimiento a su cometido una vez vencido el plazo.

Conforme a las reglas del Código Civil, el acreedor no tiene opción en principio, salvo en los casos regulados excepcionalmente en el artículo 1496 del Código Civil ${ }^{1}$ en los cuales puede solicitar de forma anticipada el pago de la obligación. En cualquier otro caso en el cual, encontrándose pendiente el plazo, es fehaciente que el deudor no va a cumplir, al acreedor no le queda más remedio que esperar la llegada del mismo, para que se verifique el incumplimiento, se constituya en mora el deudor y ejercer recién la acción que mejor satisfaga su interés, dentro de las cuales se encuentra la resolución del contrato. Esta situación, que supone que no se cumplirá con la finalidad que cada una de las partes perseguía al momento de celebrar el contrato, claramente puede traer consecuencias al acreedor de la obligación que no se va a cumplir, principalmente económicas, toda vez que su interés no se verá satisfecho. Según lo señala Álvaro Vidal, ${ }^{2}$ actualmente existe un desajuste entre el fenómeno del tráfico jurídico y las normas dispositivas del Código Civil en materia de obligaciones y la interpretación de ellas. A la época de dictación del Código Civil, las obligaciones que primaban eran aquellas de especie o cuerpo cierto, de manera tal, que el interés del acreedor únicamente se veía satisfecho en la medida en que le fuera entregada la única cosa objeto de la obligación. Sin embargo, hoy en día, la situación es inversa. Lo que prima en materia de intercambio de bienes, son aquellas obligaciones fungibles, así como

1 Artículo 1496 Código Civil: $1^{\circ} \mathrm{Al}$ deudor que tenga dicha calidad en un procedimiento concursal de liquidación, o se encuentre en notoria insolvencia y no tenga la calidad de deudor en un procedimiento concursal de reorganización. $2^{\circ} \mathrm{Al}$ deudor cuyas cauciones, por hecho o culpa suya, se han extinguido o han disminuido considerablemente de valor. Pero en este caso el deudor podrá reclamar el beneficio del plazo, revocando o mejorando las cauciones.

2 VIDAL, Álvaro: "La noción de incumplimiento esencial en el Código Civil”. En: Revista de Derecho de la Pontificia Universidad Católica de Valparaiso, XXXII, primer semestre, 2009, pp. $221-258$. 
también los servicios, de manera tal que el interés del acreedor queda satisfecho con cualquier cosa o actividad que coincida con el objeto ideal de la obligación, y ese interés tiene tantas posibilidades de ser satisfecho, como opciones existan en el mercado. ${ }^{3}$

Ahora bien, si nos enfocamos en la realidad actual de tráfico jurídico, y consideramos el caso de un acreedor de una obligación sujeta a plazo, en la cual el deudor debe entregar una cosa fungible ${ }^{4}$, y sea por la razón que sea dentro de las que se analizarán más adelante, el acreedor toma conocimiento que el deudor al llegar al plazo, no va a cumplir su obligación; no existiría razón alguna, más que la regulación expresa de la materia, para obligar a acreedor a mantenerse en esta situación, que desde ya le puede estar generando perjuicio económico, cuando existen infinitas posibilidades a las que puede optar, disponibles en el mercado. Lo anterior cobra relevancia, atendido a que si la obligación es de objeto fungible, por regla general puede ser satisfecha con cualquier otra cosa de iguales características que sea ofrecida por el mercado, de manera tal, que si el acreedor, tiene la posibilidad de liberarse rápidamente del contrato, queda habilitado entonces para celebrar una operación de reemplazo, que en corto plazo le permita satisfacer sus intereses. Respecto de la posibilidad de poder celebrar una operación de reemplazo, Cristóbal Peña Mardones, sostiene que efectivamente "este remedio resulta ser sustancial y cualitativamente superior a los restantes, particularmente, si se considera que toma en cuenta el interés del acreedor que difícilmente se verá satisfecho con el cumplimiento forzado del contratante reticente a cumplir con su obligación que ya fue negligente en el desarrollo de ésta, quebrantando la confianza depositada por el contratante."5

Dicho lo anterior y a falta de norma expresa que permita resolver aquella situación en la cual se encuentre un acreedor frente a un incumplimiento inminente de una obligación sujeta a plazo, respecto de la cual él tenga la certeza absoluta de que el deudor no va a cumplir en tiempo y forma,

3 Ídem.

4 Consideramos a las obligaciones de objeto fungible, por el hecho de que son aquellas que priman en el tráfico jurídico actual. No quiere decir que el incumplimiento previsible no pueda ser una situación que ocurra en una obligación de especie o cuerpo cierto, sino que para efectos de esta investigación, nos incumbe lo que ocurre con aquellas de objeto fungible, toda vez que suponen un muy buen ejemplo para graficar el objeto de esta investigación.

5 PEÑA, Cristóbal: "La autonomía de la voluntad en el derecho comparado. Nuevos paradigmas de la contratación moderna". En: Revista de Derecho, № 32, 2014. pp. 79-100. 
el objeto del presente trabajo consiste en determinar si es que existe la posibilidad de, mediante una interpretación armónica de las reglas existentes, aplicar en nuestro país la doctrina de la resolución el contrato por incumplimiento anticipado del mismo. Atendida la naturaleza fungible de las obligaciones que constituyen aquellas que predominan en el tráfico jurídico actual y el carácter utilitario del contrato, en orden a que es un instrumento concebido para la satisfacción de los intereses de las partes contratantes, es que no es provechoso mantener vinculadas jurídicamente a las partes a un contrato que no está cumpliendo con su finalidad y que no les está reportando a ninguna de ellas, beneficio económico alguno.

\section{LA RESOLUCIÓN COMO REMEDIO FRENTE AL INCUMPLIMIENTO CONTRACTUAL. TRATAMIENTO DEL NUEVO DERECHO DE LA CONTRATACIÓN. ${ }^{6}$}

Son variadas las posibilidades que puede ejercer el acreedor en caso de incumplimiento, sin embargo, el remedio que nos atañe en el presente trabajo, es la resolución del contrato. Deja de ser vista la resolución por incumplimiento como el efecto de una condición cumplida que trae como consecuencia la terminación del contrato, sino que pasa a ser considerada como un remedio contractual más, de entre los cuales puede optar el acreedor para satisfacer su interés. ${ }^{7}$ En virtud del objeto de este trabajo que supone tratar el tema de la posibilidad de resolver el contrato en forma previa a que se produzca efectivamente el incumplimiento en aquellos casos en que al acreedor le consta fehacientemente que este se va a producir, es importante considerar el objeto económico que tiene para las partes resolver el

6 MEJÍAS, Claudia: “El incumplimiento resolutorio en el Código Civil”. Primera Edición. Editorial Legal Publishing, Santiago, 2011.

7 FUEYO, Fernando: "Cumplimiento e incumplimiento de las obligaciones". Editorial Jurídica de Chile. Santiago, Tercera edición actualizada, 2015. p. 314. El autor se esmera en hacer hincapié en que el derecho de resolución tiene vida y causa propias que lo distinguen de la condición resolutoria tácita. La condición como figura jurídica, constituye algo que ha nacido de la voluntad y solo de ésta; por tanto, ella no surge sino cuando la voluntad la incorpora al contrato. En cambio, la acción resolutoria del artículo 1489 del Código Civil- a pesar de sus términos- no nace de la voluntad sino de la ley, o, más exactamente del diseño estatutario que la ley ha dispuesto para ciertas figuras contractuales. El profesor Morales Moreno señala que el hecho de que el derecho romano no reconociera a la resolución como figura general y que en el Código Civil español esté situada en la regulación de la condición, artículo1124 (misma situación que ocurre en nuestro país), fuera del incumplimiento, ha contribuido a oscurecer su naturaleza. Hoy en día, se abre paso la idea de que el fundamento último de la resolución 
contrato, según el profesor Morales Moreno "La función económica de la resolución, es permitir al contratante insatisfecho recuperar los recursos utilizados en el contrato incumplido, para darles otro destino". "Lo anterior se torna sumamente relevante cuando tomamos en consideración que hoy en día en el tráfico jurídico priman las obligaciones sinalagmáticas de objeto fungible. ${ }^{9}$ La razón: una obligación de objeto fungible, como se señaló mas arriba, supone que acreedor queda satisfecho con cualquier cosa o actividad que coincida con el objeto ideal de la obligación, es decir, las posibilidades de satisfacción corresponden a todas aquellas disponibles en el mercado. Esto, sumado al carácter instrumental que tiene el contrato para los intereses del acreedor, al abanico de remedios contractuales entre los cuales puede elegir en caso de incumplimiento, según la utilidad que cada uno de ellos reporte a la satisfacción de sus intereses, y a la variada gama de posibilidades que ofrece el mercado de obtener una operación de reemplazo en forma rápida y eficiente, hace que la resolución se transforme en un remedio que cobre mayor grado de relevancia en el ámbito jurídico. Lo cual es sumamente importante para efectos del presente trabajo, toda vez que, si el acreedor se enfrenta a un incumplimiento inminente del contrato, incluso antes de la llegada del plazo que torna exigible la obligación, ese contrato deja de ser útil a sus intereses. La resolución del vínculo contractual supone una opción rápida para dejar de estar obligado - por aplicación el efecto liberatorio del remedio- ${ }^{10}$ y volver al mercado a celebrar una relación contractual que si le permita obtener aquello que no obtuvo con el fallido contrato.

Dos son las características fundamentales que propone el nuevo sistema respecto de la resolución: ${ }^{11}$ por una parte, su carácter objetivo, que funda su procedencia no en la culpa si no en el incumplimiento, entendiendo al incumplimiento en su carácter amplio y objetivo. De manera tal que resulta absolutamente irrelevante si el deudor se aparta de la regla contractual por un hecho o culpa suyo o por alguna causal de imposibilidad, el acreedor siempre puede desligarse del contrato y sus efectos. Y por otra, atendido a

es el incumplimiento, y que es, por tanto, un remedio más frente al incumplimiento en las obligaciones sinalagmáticas. MORALES MORENO, Antonio Manuel: La Modernización del Derecho de las Obligaciones. Editorial Thomson Reuters Civitas, Madrid, 2006. p. 43.

8 MORALES, op. cit, pp. 43 ss.

9 VIDAL, op cit., pp. $221-258$.

10 VIDAL, op. cit., pp. $221-258$.

11 MORALES, op. cit., pp. 42 ss. 
que la resolución es considerada como una excepción a la fuerza obligatoria de los contratos, se establece por el nuevo sistema, que el incumplimiento debe tener una cierta magnitud para justificar la aniquilación del contrato por su causa. Frente a esto y tal como lo establece la Convención de Viena $\mathrm{y}$ otros textos de derecho uniforme, ${ }^{12}$ el incumplimiento debe ser esencial;

12 Convención de Viena sobre Compraventa Internacional de Mercaderías. Artículo 25: "El incumplimiento del contrato por una de las partes será esencial cuando cause a la otra parte un perjuicio tal que la prive sustancialmente de los que tenía derecho a esperar en virtud del contrato, salvo que la parte que haya incumplido no hubiera previsto tal resultado y que una persona razonable de la misma condición no lo hubiera previsto en igual situación."

- Principios de Derecho Europeo de los Contratos. "Artículo 8:103: Incumplimiento esencial: El incumplimiento de una obligación es esencial para el contrato: (a) Cuando la observancia estricta de la obligación pertenece a la causa del contrato. (b) Cuando el incumplimiento prive sustancialmente a la parte perjudicada de lo que legítimamente podía esperar del contrato, salvo que la otra parte no hubiera previsto o no hubiera podido prever en buena lógica ese resultado. (c) $\mathrm{O}$ cuando el incumplimiento sea intencionado y dé motivos a la parte perjudicada para entender que ya no podrá contar en el futuro con el cumplimiento de la otra parte." - Principios de Unidroit. "Artículo 7.3.1 (Derecho a resolver el contrato)

(1) Una parte puede resolver el contrato si la falta de cumplimiento de una de las obligaciones de la otra parte constituye un incumplimiento esencial. (2) Para determinar si la falta de cumplimiento de una obligación constituye un incumplimiento esencial se tendrá en cuenta, en particular, si: (a) el incumplimiento priva sustancialmente a la parte perjudicada de lo que tenía derecho a esperar en virtud del contrato, a menos que la otra parte no hubiera previsto ni podido prever razonablemente ese resultado; (b) la ejecución estricta de la prestación insatisfecha era esencial según el contrato; (c) el incumplimiento fue intencional o temerario; (d) el incumplimiento da a la parte perjudicada razones para desconfiar de que la otra cumplirá en el futuro; (e) la resolución del contrato hará sufrir a la parte incumplidora una pérdida desproporcionada como consecuencia de su preparación o cumplimiento. (3) En caso de demora, la parte perjudicada también puede resolver el contrato si la otra parte no cumple antes del vencimiento del período suplementario concedido a ella según el Artículo 7.1.5."

- Marco Común de Referencia: "III. - 3:502: Termination for fundamental nonperformance (1) A creditor may terminate if the debtor's non-performance of a contractual obligation is fundamental. (2) A non-performance of a contractual obligation is fundamental if: (a) it substantially deprives the creditor of what the creditor was en- titled to expect under the contract, as applied to the whole or relevant part of the performance, unless at the time of conclusion of the contract the debtor did not foresee and could not reasonably be expected to have foreseen that result; or (b) it is intentional or reckless and gives the creditor reason to believe that the debtor's future performance cannot be relied on."

- Principios Latinoamericanos de los Contratos. "Artículo 87. Carácter esencial del incumplimiento. Se entiende que el incumplimiento es esencial cuando: (a) Las partes así lo han acordado respecto de obligaciones determinadas o de supuestos específicos de incumplimiento. (b) Es doloso. (c) La conducta del deudor incumplidor hace perder 
esto es, que tenga la magnitud tal que permita justificar la aniquilación del contrato, toda vez que debe ser ponderado con el principio de fuerza obligatoria de los contratos. ${ }^{13}$ Ahora bien, respecto de lo que sucede en el ámbito nacional, a pesar de lo que establece el artículo 1489 del Código Civil, en el cual no se distingue qué clase de incumplimiento hace lugar a la aplicación del remedio resolutorio, ya nadie discute que el incumplimiento debe tener una cierta entidad para justificar la resolución. ${ }^{14}$ Sin embargo, la doctrina no está conteste en orden a qué debe entenderse entonces por esencial, ${ }^{15}$ con todo, para efectos de la presente investigación, la postura del profesor Vidal resulta ser la más acertada: "Lo que verdaderamente importa, es el incumplimiento en sí mismo y su impacto en el interés del acreedor, cuestión que-como afirma Fueyo Laneri- el juez deberá examinar caso a caso según el contenido del contrato y su economía; y también, la posible vulneración al principio de buena fe objetiva". ${ }^{16}$

En este sentido, la resolución en cuanto mecanismo de tutela ${ }^{17}$ del acreedor es un remedio que tiene una operación simple, toda vez que permite que el acreedor se desvincule del contrato que ya no le resulta útil, ${ }^{18}$ quedando sin efecto la relación contractual, liberando al acreedor de cumplir por su parte la obligación. El profesor Contardo señala respecto del efecto liberatorio de la resolución: “...permitiéndole volver al mercado (con mayor o menor rapidez dependiendo de la eficacia del sistema resolutorio)

razonablemente al acreedor la confianza en el cumplimiento posterior del contrato. (d) Prive sustancialmente al acreedor de aquello que podía esperar de acuerdo con lo que era previsible para las partes al tiempo de celebrarse el contrato. (e) El deudor no cumple dentro del plazo de subsanación del artículo 93."

13 VIDAL, op. cit., pp. 221 a 258.

14 FUEYO, op. cit., p. 312. El autor se refiere al cambio de paradigma que ha tenido la doctrina nacional, incluyendo una autocrítica a su propia postura, la cual cambió con los años. En relación al requisito de la esencialidad del incumplimiento, necesaria para ejercer la acción resolutoria señala: "Estimo que la resolución no puede proceder siempre, cualquiera que sea la importancia, entidad o trascendencia de los incumplido. Descarto, pues dicha posición extrema e intransigente que fue la que imperó en Chile"

15 VIDAL, op. cit. pp. 221 - 258.

16 Ídem.

17 CONTARDO, Juan Ignacio: “Indemnización y resolución por incumplimiento". Editorial Legal Publishing, Santiago, 2015. p. 52. El carácter tutelar del remedio resolutorio se manifiesta precisamente en la posibilidad de liberarse de la obligación y obtener restitución de lo pagado.

18 GALVÁN, José Antonio: "Conferencia Inaugural del II Congreso Chileno de Derecho privado”. En: Revista de Derecho de la Universidad Católica de Valparaíso, XIV, 1998. Pp. 13-20. 
para cubrir sus intereses". ${ }^{19} \mathrm{Si}$ tomamos en consideración la noción realista, funcional, instrumental de la resolución, propia del nuevo derecho de la contratación, la razón por la cual las partes se mantienen ligadas a una relación contractual es porque en virtud de ella podrán satisfacer los intereses que tenían en miras de satisfacer al momento de su celebración. $\mathrm{Si}$ la parte acreedora considera que efectivamente sus intereses no se verán satisfechos con el actuar de la contraria, el contrato se torna inútil y conforme a la rapidez del tráfico jurídico actual, no le resulta conveniente seguir ligada a una relación contractual que no será fructífera. Por tanto, es altamente probable (dependiendo del caso en concreto por supuesto), que sea mucho más conveniente a sus intereses, desvincularse del contrato para poder rápidamente celebrar una operación de reemplazo. A mayor abundamiento, si estamos pensando en un incumplimiento de carácter anticipado, en el que el acreedor objetivamente toma conocimiento de que el incumplimiento se va a producir una vez llegado el plazo, significa que considera que el contrato ya no es útil a sus intereses, por tanto, no tendría por qué querer seguir vinculado a él y sí preferir la liberación del vínculo contractual para poder volver al mercado a buscar otras opciones. Por otra parte, el hecho de que un contrato no resulte útil a los intereses del acreedor toda vez que se incumple puede generar una serie de desventajas al acreedor que no solamente se van a ver satisfechas una vez que el efecto liberatorio de produzca. Por una parte, desvincularse del contrato le permite no seguir ligado al mismo, el cual, no será cumplido por la contraria, toda vez que podría estar invirtiendo en la celebración de una relación contractual que si efectivamente satisfaga sus intereses. En este sentido el profesor Contardo señala: "El incumplimiento del contrato, a pesar de la liberación puede significar un conjunto de desventajas, gastos y daños sufridos por el acreedor, que no solo se remedian por el hecho de la liberación de cumplir. La liberación solo le permite al acreedor no invertir más en un contrato que no le ha sido cumplido por la otra parte. Tampoco, como se verá, el efecto restitutorio de la resolución permite al acreedor remediar el daño que ha sufrido por el incumplimiento. Solo le permite recuperar lo que ha pagado en virtud del contrato resuelto". ${ }^{20} \mathrm{Si}$ el acreedor logra acreditar que su deudor ha incurrido en un incumplimiento anticipado del contrato, toda vez que en virtud de hechos objetivos, por ejemplo, la declaración expresa de que no cumplirá el contrato en tiempo y forma, toma conocimiento de que el

19 CONTARDO, op. cit., 23 ss.

20 CONTARDO, op. cit., p. 125. 
contrato no se va a cumplir, podría ejercer la acción de resolución del contrato antes de que el plazo se venza permitiéndole reducir ${ }^{21}$ significativamente una serie de perjuicios económicos que le generaría el hecho de esperar a

21 En el caso en que el acreedor opte por solicitar la resolución anticipada del contrato, en relación a los daños que se producirían como consecuencia del incumplimiento, estaría contribuyendo a evitarlos desde dos aristas: por una parte estaría cumpliendo con su deber de mitigarlos y al hacerlo estaría habilitado para demandar la totalidad de los perjuicios que hasta ese momento le hubiese provocado el incumplimiento y que sean imputables a la conducta del deudor. Y por otra, puede demandar los daños incidentales, esto es, los generados por haber cumplido con su deber de mitigar los daños. En este sentido se pronuncia el profesor Juan Ignacio Contardo González, op. cit. Más allá de adentrarnos en el problema de determinar si efectivamente nuestro ordenamiento jurídico daría lugar o no a reconocer el deber de mitigar los daños, el profesor Carlos Pizarro, propone la idea, respecto de este tema, tomar en cuenta la finalidad práctica y económica del contrato, en orden a considerar que el ejercicio del deber de minimizar los daños permite un resultado más eficiente desde un punto de vista económico. Señala el autor expresamente: "Una vez producido el incumplimiento, no debemos impulsar el fatalismo en el acreedor, quedando pasivo frente a consecuencias nocivas de la inejecución. Aún en un sistema que otorgue a la ejecución forzada una categoría superior frente a otras sanciones que aniquilan el contrato, no parece justificarse la pasividad del acreedor que mira el desastre impávido pudiendo aportar a una mejor solución del problema que le aqueja". Es sumamente importante considerar la finalidad práctica que tiene para las partes la relación obligacional que las liga, así como también la consideración al interés económico de las mismas en el contrato. Es en virtud de esto que para el acreedor resultará útil terminar con el contrato, en cuanto le conste fehacientemente que el deudor no cumplirá su obligación al llegar el plazo acordado, porque no se encontrará obligado a mantenerse en una relación contractual infructuosa y que le genera perjuicios, tanto a él como al deudor seguramente también. Perjuicios que deberá indemnizar el deudor en caso de que así lo solicite el acreedor y lo declare el juez. PIZARRO, Carlos. "Contra el fatalismo del perjuicio a propósito del deber de mitigar el daño". En: Revista de Derecho de la Pontificia Universidad Católica de Valparaíso, XLI 2013, $2^{\circ}$ semestre, pp. 6982. Considerando la realidad actual del trafico jurídico, mantenerse entonces en esta situación de perjuicio que probablemente irá en aumento en la medida en que pase el tiempo, no beneficia ni al acreedor ni al deudor, entonces que el primero contribuya a aminorar los perjuicios patrimoniales que los afectarían, supone una actividad de toda lógica y buena fe, respecto de la ejecución del contrato. El deber de mitigar daños también tiene reconocimiento a nivel de normativa internacional. Por ejemplo, en la CISG, está previsto en su artículo 77, el cual establece: "La parte que invoque el incumplimiento del contrato deberá adoptar las medidas que sean razonables, atendidas las circunstancias, para reducir la pérdida, incluido el lucro cesante, resultante del incumplimiento. Si no adopta tales medidas, la otra parte podrá pedir que se reduzca la indemnización de los daños y perjuicios en la cuantía en que debía haberse reducido la pérdida". En este caso, el acreedor que invoca el incumplimiento por su contraparte, debe contribuir a reducir los efectos negativos de este hecho, debe adoptar razonablemente las medidas que según las circunstancias propias de cada caso. 
que el plazo se cumpla para que se configure el incumplimiento, y recién en ese momento demandar la resolución del contrato.

\section{RESOLUCIÓN ANTICIPADA DEL CONTRATO}

\section{1.- Contexto.}

Nos ubicamos en el contexto de un contrato que contiene obligaciones sujetas a plazo, de manera tal que no son exigibles sino hasta la llegada del mismo, pero que, sin embargo, el acreedor por motivos diversos y hechos objetivos, ha tomado conocimiento o tiene la cierta sospecha de que el deudor no cumplirá su cometido en tiempo y forma. El derecho uniforme y la doctrina extranjera ha analizado la situación anterior configurando la idea de protección anticipada a los intereses del acreedor, frente a un incumplimiento previo a la llegada del plazo, identificando dos figuras que permiten este tipo de protección: por una parte la suspensión del cumplimiento de la obligación del acreedor y por otra, la resolución anticipada del contrato. ${ }^{22}$

En cuanto a la suspensión del cumplimiento de la prestación del acreedor, supone una medida que permite al acreedor mantener la prestación en su poder aun cuando su obligación se ha hecho exigible. En el caso, no se requiere de un incumplimiento recíproco, sino únicamente de la existencia del temor de que la contraparte no cumplirá, lo cual justificaría la suspensión del propio cumplimiento. ${ }^{23}$

Por otro lado, la resolución anticipada del contrato se trata de una modalidad de ejercicio de la resolución que permite al acreedor poner fin a una relación contractual antes de que el deudor incumpla su obligación cuando la inejecución aparece en forma inminente. ${ }^{24}$

\section{2.- Regulación a nivel internacional y requisitos de procedencia.}

En la actualidad, la regla de la resolución mediante el incumplimiento anticipado o la anticipatory non performance o anticipatory breach of the

22 CONTARDO, Juan. "La resolución por incumplimiento previsible y la suspensión del cumplimiento como medios de tutela anticipatoria del acreedor". En: Ian Henríquez Herrera (Coordinador). La compraventa. Nuevas perspectivas doctrinarias. Editorial Thomson Reuters, Santiago, 2015. pp. 155-180.

23 Ídem.

24 Ídem. 
contract se encuentra ya consagrada en algunos ordenamientos jurídicos, así como también, tiene amplia regulación en el derecho uniforme.

Respecto de los ordenamientos jurídicos internos, hay variadas manifestaciones de regulación de la doctrina en comento, por ejemplo, en el Código Civil Holandés de 1992 (§ 6:10), en el Código Civil Alemán de 2002 (§323), en el Nuevo Código Civil y Comercial Argentino de 2015 (artículo 1084 letra e)), así como también en la Propuesta de Reforma al Código Civil Español (artículo 1200).

Por su parte, el derecho uniforme también se hace cargo de la regulación de la doctrina de la resolución por incumplimiento anticipado, en cuerpos normativos como la Convención de Viena sobre Compraventa Internacional de Mercaderías, los Principios de Derecho Europeo de los Contratos, Principios de UNIDROIT sobre los Contratos Comerciales Internacionales, el Marco Común de Referencia y los Principios Latinoamericanos de Derechos de los Contratos (PLDC). Considerando como mayor referente respecto de este tema a la Convención de Viena, atendido a que es el único cuerpo normativo de los nombrados, que ha sido ratificado por nuestro país y constituye ley de la República, sin descuidar a los PLDC, los cuales miran a la propuesta de uniformidad del derecho regional. El elemento que tienen en común estos cuerpos normativos, consiste en que todos se hacen cargo de la posibilidad de prever el incumplimiento y ofrecer una protección anticipada al acreedor en caso de que se vea enfrentado a esta situación, otorgándole la posibilidad de impetrar dos remedios contractuales diversos, en la medida en que se configuren los requisitos de aplicación de cada uno de ellos: Por una parte existe la posibilidad de suspender el propio cumplimiento hasta el momento en que el deudor otorgue garantías suficientes de cumplimiento, y por otra, la posibilidad de derechamente resolver el contrato, en cuanto sea inminente que el incumplimiento se va a producir y que este cumpla con los requisitos de esencialidad. A continuación, los enunciamos:

- Artículo 71, 72 y 73 de la Convención de Naciones Unidas Sobre Compraventa Internacional de Mercaderías o Convención de Viena (CISG).

- Artículos 8:105 y 9:304 de los Principios de Derecho Europeo de los Contratos (En adelante PECL).

- Artículos 7.3.3 y 7.3.4 de los Principios de Unidroit sobre los Contratos Comerciales Internacionales. 
- Artículos 3:401 y 3:504 del Marco Común de Referencia.

- Artículos 97 y 103 de los Principios Latinoamericanos de Derechos de los Contratos.

De la revisión de cada uno de los cuerpos legales ya referidos que consagran la figura objeto de estudio, podemos arribar a lo que se denomina "elementos rectores de la resolución por anticipación" 25 , conforme al siguiente detalle:

a.- Se asimila el incumplimiento previsible al incumplimiento "actual" para resolver el contrato. Este incumplimiento que se prevé permite resolver ${ }^{26}$ el contrato con las mismas consecuencias que tiene la resolución que se produce como consecuencia de un incumplimiento efectivo. ${ }^{27}$

25 CONTARDO, op. cit., pp. 155-180.

26 Uno de los cuatro modelos de resolución que es posible advertir a nivel de derecho comparado corresponde a la resolución extrajudicial por notificación al acreedor. Este modelo ha sido incorporado por el BGB alemán desde la reforma del año 2002 y supone que el ejercicio de la acción resolutoria no se realiza por vía judicial, sino el acreedor simplemente notifica al deudor su voluntad de que se produzca la extinción del contrato, $\S 349$ BGB. CONTARDO, op. cit., pp. 106 ss. A nivel de normativa de derecho uniforme así se ha estipulado, por ejemplo: Art. 26 CISG, Art. 7.3.1 Principios de Unidroit, Art. 9.301 PECL. También esta forma de resolver el contrato ha sido recogida por los Principios Latinoamericanos de Derechos de los Contratos en su artículo 97 al señalar “1) Cualquiera de las partes puede resolver el contrato cuando la otra haya incurrido en un incumplimiento esencial. (2) El incumplimiento reciproco no impide la resolución del contrato. (3) La resolución puede ser judicial o por comunicación.” Esto último resulta relevante toda vez que los Principios Latinoamericanos, suponen un esfuerzo de destacados juristas en aplicar las nuevas tendencias a nivel de derecho comparado contractual al derecho regional a modo de referencia para los ordenamientos jurídicos locales. En Chile, la acción resolutoria debe ser ejercida por la vía judicial. Lo anterior se desprende de lo establecido en el artículo 1489 CC, el cual al utilizar la voz "pedir", nos indica que el acreedor debe solicitar el remedio escogido en virtud de una demanda judicial, y claramente debemos considerar a los textos de derecho uniforme únicamente como guía para interpretar nuestras instituciones, como ocurre en el caso del presente trabajo. Si bien es cierto que en Chile no procede la resolución por notificación a la parte contraria en caso de incumplimiento, más aun pensando en la resolución por incumplimiento anticipado, ya es un indicio muy bueno que haya sido considerada en el texto de los PLDC. Con todo, el presente trabajo no tiene por objeto tratar de configurar la resolución por incumplimiento anticipado del contrato, considerando a la resolución como remedio que puede operar por la sola notificación al deudor incumplidor, sino considerando al remedio resolutorio tal como está regulado en el Código Civil, esto es, con su procedencia a petición de parte en virtud del ejercicio de la acción resolutoria, pero con las variantes - producto de la interpretación de las normas a la luz del Nuevo Derecho de la Contratación - que trataremos mas adelante.

27 Tal como se indicó anteriormente, las partes quedan liberadas del vínculo contractual lo cual permitiría a la parte perjudicada, volver al mercado a celebrar una operación de reemplazo que le permita efectivamente satisfacer sus intereses. Art. 75 y 76 CISG. 
b.- El incumplimiento que se prevé, debe ser esencial. En todos los textos normativos que analizamos más arriba, se exige que el incumplimiento que se teme que ocurra, va a ser un incumplimiento que habilita al acreedor a declarar resuelto el contrato. Resulta de toda lógica que así lo sea, si consideramos que al incumplimiento se lo está tratando o equiparando con el incumplimiento efectivamente producido.

Se ha señalado ${ }^{28}$ que lo que ha ocurrido a nivel de derecho comparado es que se han simplificado los requisitos para resolver el contrato, exigiendo siempre el requisito de la esencialidad del incumplimiento. La autora señala: "Asi ha ocurrido en el BGB en el que la mayor facilidad que tiene el acreedor para resolver el contrato, no va en detrimento del principio pacta sunt servanda, sino que por el contrario, garantiza una mayor justicia contractual "29. Es la esencialidad del incumplimiento lo que permite ponderar el respeto por la fuerza obligatoria del contrato y de la palabra empeñada; con el equilibro y la justicia contractual que debe existir en una relación obligacional ${ }^{30}$.

c.- No debe haber lugar a ninguna duda de que el deudor no ejecutará su prestación en tiempo y forma, o bien que aparezca como muy probable. Según el Compendio de Jurisprudencia basada en la CISG de Naciones Unidas, "se requiere más que una certeza absoluta, que exista una probabilidad muy fuerte de que sobrevenga un incumplimiento esencial"'31.

28 PÉREZ, Rosana: "El incumplimiento esencial del contrato como categoría independiente del incumplimiento resolutorio en la Jurisprudencia del Tribunal Supremo". En: Revista Critica de Derecho Inmobiliario, No 752 , pp. 3680 a 3693.

29 Ídem.

30 Ídem. Agrega además, lo siguiente: "El remedio resolutorio tiene como fundamento común en todos los sistemas la equidad y el sinalagma. En los contratos sinalagmáticos o bilaterales cada una de las partes solo está obligada a realizar su prestación bajo reserva de recibir la que le ha sido prometida y en consecuencia, frente al incumplimiento de la otra parte, el perjudicado tiene derecho a liberarse de la obligación que le incumbe". Tal como lo tratamos en el capítulo anterior, en materia de ejercicio de los remedios contractuales, priman los intereses de las partes y el carácter instrumental que tiene el contrato en si mismo para la satisfacción de dichos intereses. Si el contrato antes de la llegada del plazo de cumplimiento, se prevé no será útil al acreedor, se promueve la simplicidad para desvincularse del mismo a fin de poder celebrar una operación de reemplazo que le resulte fructífera.

31 Compendio de Jurisprudencia basada en la Convención de las Naciones Unidas sobre los contratos de Compraventa Internacional de Mercaderías. Fuente: https://www.uncitral. org/pdf/spanish/clout/Second_edition_spanish.pdf 


\section{3.- Análisis de casos.}

A continuación, analizaremos cinco situaciones respecto de las cuales consideramos es posible resolver anticipadamente el contrato a la luz de nuestro ordenamiento jurídico, esto es: disminución de la fortuna del comprador, anuncio de parte del deudor de que no cumplirá su cometido, pérdida de confianza, autonomía privada e imposibilidad sobrevenida.

3.1.- Cuestión previa: en cuanto a constitución en mora como requisito para el ejercicio de la acción resolutoria.

Previo a comenzar el análisis de aquellas situaciones respecto de las cuales sería posible aplicar en nuestro país la resolución del contrato en forma anticipada al vencimiento del plazo, es necesario hacer presente que adherimos a aquella postura que señala que la constitución en mora es un requisito necesario únicamente para el ejercicio de la acción indemnizatoria, mas no para la acción resolutoria. ${ }^{32}$ No es del caso del presente trabajo realizar un análisis pormenorizado de la figura de la constitución en mora en materia de resolución del contrato, sin embargo, la adhesión a la postura anterior resulta determinante para la argumentación de la presente investigación, toda vez que, al ejercer el remedio resolutorio respecto de una obligación en la cual se encuentra pendiente el plazo de cumplimiento, es altamente probable que no se haga lugar a la solicitud, por no encontrarse el deudor constituido en mora, toda vez que la tónica en nuestro sistema es que se haya entendido a la constitución en mora como un requisito de ejercicio de la acción resolutoria. Sin perjuicio de lo anterior, como señalan Hugo Cárdenas y Ricardo Reveco, son dos las razones por las cuales el papel que juega la mora en el ejercicio de la acción resolutoria es confusa: "La primera, obedece al hecho de que el numeral tercero del artículo 1551 CCCh. se consagra - cómo cláusula de cierre - la constitución en mora del deudor mediante la interpelación judicial. Así, siendo requisito de la acción de resolución del contrato su ejercicio judicial, mediante la invocación de la condición resolutoria tácita, el deudor siempre se encontrará en mora al notificársele judicialmente la resolución del contrato. De esta manera, la mora como requisito de la resolución del contrato no ofrecería ninguna funcionalidad relevante. La segunda, obedece al hecho de que mientras el artículo 1557 CCCh. exige la constitución en mora del deudor para que se pueda ejercitar la acción indemnizatoria, el artículo 1489 CC Ch

32 MEJÍAS, op. cit., p. 30. 
no contempla esa exigencia de forma expresa." ${ }^{33}$ Según profundiza el profesor Juan Ignacio Contardo, "Si se mira desde el punto de vista de la gravedad del incumplimiento, la resolución ya se encuentra activada: hay incumplimiento y es de gravedad (resolutorio). La mora, como sinónimo de retardo culpable, no juega ninguna función verdaderamente relevante, puesto que la intención del acreedor ha sido dar fin a la relación obligatoria en aras de no encontrarse más obligado en virtud del pacto contractual". ${ }^{34}$

Consideramos que esta postura se vincula con la posibilidad de ejercer la acción resolutoria en forma anticipada, principalmente en aquello relativo al requerimiento que debe hacer el acreedor al deudor. Conforme se desprende del artículo 1551 del Código Civil, el requerimiento puede ser contractual (establecido en el propio contrato, conforme al cual las partes han estipulado un plazo para que la obligación se cumpla) o bien extracontractual (posterior al nacimiento de la obligación, materializándose en nuestro derecho, mediante la interposición de la demanda judicial). El contexto en el cual se sitúa nuestra hipótesis, nos encontramos frente a una obligación sujeta a plazo, en la cual el acreedor, confirma con anterioridad a su vencimiento, que la misma, al llegar el plazo no va a ser cumplida, de manera tal que por una parte estamos en presencia de una obligación que en principio aún no es exigible, porque el plazo fijado en el contrato aún se encuentra pendiente, pero respecto de la cual se podría demandar la resolución del contrato, sin estar el deudor constituido en mora:

a.- Porque la constitución en mora es un requisito únicamente para el ejercicio del remedio indemnizatorio.

b.- Porque el plazo aún se encuentra pendiente de manera tal que, al solicitar la resolución anticipada del contrato, mal podría encontrarse constituido en mora el deudor en virtud de un requerimiento contractual.

c.- La constitución en mora se va a producir al momento del ejercicio de la acción resolutoria.

33 CÁRDENAS, Hugo, Reveco, URZÚA Ricardo: Remedios contractuales. Clausulas, acciones y otros mecanismos de tutela del crédito. Editorial Legal Publishing, Santiago. p. 356

34 CONTARDO, op. cit,. p. 226. En el mismo sentido se ha manifestado Enrique Alcalde Rodríguez, quien señala que la mora es un requisito relacionado única y exclusivamente con la indemnización de perjuicios, no así respecto de la acción de cumplimiento ni de la resolución en "Incumplimiento reciproco, resolución y cumplimiento de contrato bilateral”. En: Revista Chilena de Derecho, Vol. 31. 2004. pp. 565-576. 
- Si existe un plazo pendiente y las partes han estipulado que el requerimiento va a ser de carácter contractual, nada obsta a que, a pesar de aquello, se pueda aplicar el $\mathrm{N}^{\circ} 3$ del artículo 1551, toda vez que señala que en todos los demás casos "que no sean" los del número 1 y 2 , se aplica la reconvención judicial. En esta hipótesis nos encontramos con una situación conforme a la cual si bien hay un plazo de cumplimiento de la obligación, pero que aún no se ha cumplido, sin embargo el acreedor sabe con certeza, y ciertamente puede acreditarlo en juicio, que no se producirá el cumplimiento de la obligación, de manera tal, que nada impide la aplicación del numeral 3 , y reconvenir judicialmente al momento de ejercer la acción resolutoria, constituirlo en mora y quedar habilitado para, conjuntamente al ejercicio de esta última demandar indemnización de perjuicios si lo requiere.

- Puede ser que la constitución en mora no se produzca, toda vez que uno de los requisitos para la misma es que el retardo del deudor sea imputable y si nos enfrentamos a la hipótesis que veremos más adelante, conforme a la cual el deudor anuncia a su acreedor que la obligación no va a ser cumplida en tiempo y forma por ejemplo por razones de fuerza mayor, ese incumplimiento no le es imputable, y cumpliendo con su obligación de aminorar los daños, anuncia esto al acreedor para desvincularse rápidamente del contrato sin generar daños que indemnizar. Eventualmente, al no ser necesario el ejercicio del remedio indemnizatorio en conjunto al remedio resolutorio, no hace necesario que el deudor se encuentre constituido en mora, y no va a ocurrir, toda vez que no se cumplirá con uno de los tres (retardo, requerimiento, imputabilidad) requisitos para entenderlo constituido en mora, la imputabilidad de los daños. De manera tal que solo se ejercerá el remedio resolutorio, al haberse cumplido los requisitos del mismo, generando como única consecuencia, la desvinculación de las partes, del contrato que las ligaba.

Si bien la doctrina nacional se ha referido a la posibilidad de resolver anticipadamente un contrato, encontrándose pendiente el plazo del mismo, lo ha hecho respecto de la obligación de pagar el precio. A continuación, analizaremos otros casos respecto de los cuales el acreedor, estando pendiente el plazo para el cumplimiento de la obligación, prevea su no ejecución al llegar el plazo, y que no necesariamente se circunscriba al incumplimiento de la obligación de pagar el precio, si no respecto de cualquier otro tipo de contrato que contenga obligaciones respecto de las cuales su no ejecución signifique incumplimiento esencial del mismo. La teoría de la resolución por incumplimiento anticipado es aplicable sin 
importar cuál sea la causa de la repudiación del contrato, toda vez que se recurre con la misma a un concepto objetivo de incumplimiento, como se ha indicado con anterioridad.

\section{2.- Análisis de casos.}

a) Disminución de la fortuna del deudor.

En relación a este primer caso, el profesor Juan Ignacio Contardo realiza una comparación entre las normas de derecho uniforme y las normas vigentes actualmente tanto en Código Civil como en el Código de Comercio, logrando plantear una posible resolución por incumplimiento anticipado del contrato en el derecho nacional, a partir de lo establecido a propósito de la suspensión de cumplimiento regulada en los artículos 1826 del Código Civil y 174 del Código de Comercio.

En relación al artículo 1826, la norma tiene aplicación respecto de una "disminución considerable" de la fortuna del comprador, lo cual según el autor, ${ }^{35}$ hace temer el cumplimiento de la obligación, es decir, el pago del precio. Si bien no se ha configurado un incumplimiento propiamente tal, toda vez que la exigibilidad de la obligación se encuentra pendiente. Conforme a lo anterior, también señala que existe una cierta correspondencia normativa del artículo 1826 con el artículo 1496 del Código Civil, ${ }^{36}$ conforme al cual se establece la caducidad del plazo. Según lo señala el autor, de la norma se desprende que igualmente existe por parte del acreedor un justo temor de que el deudor no cumplirá con su obligación, toda vez que se "halla en notoria insolvencia"; lo cual faculta al acreedor a exigir inmediatamente el cumplimiento de la obligación como si fuera de plazo vencido y así evitar que el deudor no tenga bienes a la fecha de la exigibilidad de la obligación. Además de lo anterior, menciona en el mismo sentido el artículo 147 de Código de Comercio, ${ }^{37}$ conforme al cual, en caso de producirse el "decaimiento de las facultades

35 CONTARDO, op. cit., p. 173.

36 Artículo 1496 Código Civil. "El pago de la obligación no puede exigirse antes de expirar el plazo, si no es: $1^{\circ} \mathrm{Al}$ deudor que tenga dicha calidad en un procedimiento concursal de liquidación, o se encuentre en notoria insolvencia y no tenga la calidad de deudor en un procedimiento concursal de reorganización; $2^{\circ} \mathrm{Al}$ deudor cuyas cauciones, por hecho o culpa suya, se han extinguido o han disminuido considerablemente de valor. Pero en este caso el deudor podrá reclamar el beneficio del plazo, renovando o mejorando las cauciones"

37 Artículo 147 Código de Comercio. "Si en el tiempo medio entre la fecha del contrato y el momento de la entrega hubieren decaído las facultades del comprador, el vendedor no estará obligado a entregar la cosa vendida, aun cuando haya dado plazo para el pago del precio, si no se rindiere fianza que le dé una seguridad satisfactoria. 
del comprador", el vendedor no está obligado a entregar la cosa vendida, aun cuando haya dado un plazo para el pago del precio, si no se rindiere fianza que le dé una seguridad satisfactoria. Como señala el autor, en este caso, lo determinante no es el plazo que el deudor haya dado al comprador, sino que hayan decaído sus facultades económicas. Respecto de las tres normas revisadas por el autor, podemos concluir que, si bien es cierto que el Código Civil no habla directamente de que debe existir temor por parte del vendedor de recibir el pago del precio, eso es efectivamente lo que se desprende de cada una de las normas, ya que permite que el acreedor de la obligación de pagar, no cumpla con su parte del contrato, toda vez que ve amenazado el cumplimiento respecto de la contraparte. Para que el Código razone de esa forma, creemos, que con independencia de la redacción que se presenta en cada una de las normas, esto es: "disminución considerable de la fortuna del comprador", "notoria insolvencia" y "decaimiento de las facultades del comprador", el empobrecimiento que se produce en el patrimonio del deudor no debe ser cualquiera, sino uno que tenga tal envergadura que permita formar en el acreedor la convicción de que el precio no va a ser pagado, lo cual significaría un incumplimiento esencial de la obligación en el momento en que esta naturalmente debiera cumplirse, permitiéndole ejercer en su momento la acción resolutoria. Esto es lo que precisamente no está regulado en nuestra legislación. Ante lo cual, el autor presenta dos posibles soluciones: Por una parte, se puede entender que la disminución de la fortuna del deudor, sería un supuesto calificado de caducidad del plazo, haciendo exigible la obligación, por tanto, se configuraría el incumplimiento de la obligación por parte del deudor. A pesar de no estar contenida la presente hipótesis en el artículo 1496 del Código Civil, el autor señala que al entender la obligación como de plazo vencido, configurándose de la forma descrita, un incumplimiento total de la misma, el acreedor podría instar la resolución. El inconveniente que alerta el autor a la presente opción, supone que, al adscribir a la misma, se confundiría lo que es el incumplimiento presumido con el incumplimiento de la obligación futura, toda vez que la notoria insolvencia, hecho que produce el justo temor que la prestación no sea cumplida, haciendo patente que el deudor no cumplirá, es de tiempo presente y no futuro. Es decir, la notoria insolvencia, hace que la obligación originalmente sujeta a plazo, se transforme en una obligación actualmente exigible respecto de la cual se ha configurado el incumplimiento. 
En relación a lo anterior, el profesor Peñailillo ${ }^{38}$ concuerda con la posibilidad de ejercer la acción resolutoria en la hipótesis de caducidad del plazo, toda vez que el incumplimiento se produce; haciendo el mismo autor el reparo en que el artículo 1496 únicamente se refiere a la posibilidad por parte del acreedor de exigir el "pago" de la obligación antes de expirar el plazo, dando lugar a poder solicitar únicamente el cumplimiento de la obligación, mas no su resolución. A pesar de lo anterior, la otra solución propuesta por el profesor Contardo ${ }^{39}$ podría consistir, según el autor, en asimilar los efectos de la disminución de la fortuna del comprador al incumplimiento del deudor para poder pedir la resolución, sin calificar esta situación como caducidad del plazo. Lo que sostiene el autor y con lo que concordamos, es que, en caso de caducidad del plazo, el acreedor únicamente podría solicitar el cumplimiento de la obligación, sin embargo, señala que este razonamiento no está cubierto por la norma, toda vez que el deudor no tendrá como pagar el precio, si precisamente lo que hace caducar el plazo, es el hecho de que su fortuna ha disminuido. Se torna inoficiosa la solución de la norma. A mayor abundamiento, en el caso en que el deudor tenga más de un acreedor, deberán aplicarse las normas propias de la prelación de créditos de los artículos 2465 y siguientes del código civil, caso en el cual un acreedor valista, por ejemplo, tendrá escasas posibilidades de obtener la satisfacción de su crédito, de manera tal que si tiene conocimiento de la existencia de otros acreedores con preferencia para el pago de sus créditos y que su deudor ha caído en notoria insolvencia, claramente le será mucho más conveniente solicitar anticipadamente la resolución de su contrato, antes de exponerse a ver gravemente perjudicado su patrimonio con la espera de la llega del plazo para que su deudor cumpla, lo cual es altamente probable que no ocurra.

Señala Contardo, que es en razón de lo anterior, que las normas objeto de análisis discurren sobre la base de que el acreedor pueda suspender la prestación hasta que se le otorgue garantía suficiente de cumplimiento. La no presentación de esta garantía puede configurar el incumplimiento

38 PEÑAILILLO, Daniel: "Algunas reformas a la resolución por incumplimiento". En: Revista de Derecho de la Universidad de Concepción, № 231-232, Año LXXX, EneroJunio, Julio Diciembre, 2012. Al respecto el autor indica, sin hacer mayor análisis, que la objeción no parece suficiente como para excluir esa posibilidad. Textualmente señala lo siguiente: "aunque concluyamos que se puede pedir la resolución, no se trata de un exacto equivalente, porque aqui la obligación ya está (se ha tornado) exigible, y la "anticipatory breach" implica, como se dijo, una ruptura anticipada del contrato (cuando la obligación aún no es exigible)" 
actual que permitiría el ejercicio de la acción resolutoria antes de la llegada del plazo. Respecto de los tres artículos comentados, la disminución del patrimonio del deudor genera claramente en el acreedor el temor de ver incumplida la prestación; temor que es superado, si es que el deudor paga o garantiza el pago, en el caso del artículo 1826; o si el deudor rinde fianza que le dé seguridad satisfactoria, en el caso del artículo 147 del Código de Comercio; o si el deudor renueva o mejora sus cauciones, en el caso del artículo 1946 del Código Civil. Incluimos acá también la situación contenida en el artículo 2427 del Código Civil, conforme al cual el acreedor hipotecario frente a una eventual pérdida o deterioro de la finca, supera el temor de la posibilidad de falta de garantía en su crédito en la medida en que la hipoteca sea mejorada o que consienta en que se le dé otra seguridad equivalente. Ahora bien, en la situación en que el deudor no realice ninguna de dichas acciones, el temor se mantiene de manera tal que el acreedor podrá: a) mantener la cosa en su poder, a pesar de que se haya estipulado un plazo para el pago del precio (artículos 1826 CC y 147 Código de Comercio); b) exigir el cumplimiento de la obligación (artículo 1496 CC) y c) exigir el pago inmediato de la deuda líquida, aunque se encuentre pendiente el plazo o bien implorar las providencias conservativas que el caso admita, si la deuda fuera ilíquida, condicional o indeterminada (artículo $2427 \mathrm{CC}$ ). En todos los casos, creemos, que se produce un despropósito del contrato en sí mismo, ya que ambas partes y sobre todo el acreedor, es obligado mantenerse ligado a una relación contractual que no cumplirá los objetivos que se tenían en miras al momento de celebrarlo. Por una parte, si debe mantenerse en la suspensión del cumplimiento de su obligación de entregar la cosa, por ejemplo, el temor de que el deudor no cumpla con su obligación de pagar el precio, porque su patrimonio se ha visto disminuido, a pesar de que el plazo se encuentre pendiente, aún persiste y a mayor abundamiento, se ha confirmado, toda vez que ante dicha circunstancia, el deudor no ha pagado ni ha garantizado que el pago efectivamente de producirá a pesar de su insolvencia. Y por otra parte, en caso de que no renueve ni mejore sus cauciones, el acreedor podrá solicitar el cumplimiento efectivo de la obligación, lo cual también resulta inoficioso, toda vez que es altamente probable que el deudor no cuente con los medios necesarios para cumplir cabalmente su obligación y en caso de que cuente con los recursos, deberá atenerse el acreedor a las normas sobre prelación de créditos contenidas en nuestro ordenamiento jurídico, viéndose altamente perjudicado en caso de no contar su crédito con algún privilegio o hipoteca. 
Conforme a lo anterior, pensamos que en principio no debería existir inconveniente para que el deudor pueda solicitar la resolución del contrato en la medida en que se cumplan los dos requisitos tratados más arriba: que se presente una notoria disminución de las facultades económicas del deudor y la no prestación de la garantía. Según Contardo ${ }^{40}$, con quien concordamos, no existen razones motivos para que el acreedor deba esperar al cumplimiento del plazo para solicitar la resolución del contrato, en circunstancias de que la ley ordena la prestación de la garantía en tiempo presente, y esta falta de garantía o incluso la falta de pago del precio como exige el Código Civil, puede representar el temor "patente" de que no se cumplirá la prestación en tiempo debido. ${ }^{41}$

b) Anuncio del deudor que no cumplirá la obligación dentro de plazo.

La hipótesis consiste en aquella situación en que encontrándose pendiente el plazo para el cumplimiento de la obligación por parte del deudor, este manifiesta al acreedor que por razones que perfectamente pueden ser distintas a la insolvencia patrimonial y a fuerza mayor o caso fortuito, no dará cumplimiento al contrato en el plazo que ambas partes habían acordado. La doctrina ${ }^{42}$ lo ha definido como "renuencia anticipada" y consiste en la voluntad del deudor de no cumplir lo pactado, la cual puede devenir en una repudiación anticipada que da lugar al incumplimiento. Del Favero, a su vez toma la definición de Arthur Rosett, ${ }^{43}$ el cual señala que "por repudiación se debe entender tales palabras o acciones de la parte contratante que indican que ella no ejecutará el contrato en el futuro", de manera tal que la voluntad de no dar cumplimiento al contrato se debe manifestar en forma expresa o tácita.

Lo determinante en esta hipótesis, es que la manifestación de voluntad que constituya la repudiación debe tener una entidad tal que permita generar en el acreedor el temor de que efectivamente el contrato no será cumplido en tiempo y forma, el cual será mucho más patente, cuando el deudor específicamente le comunique que no dará cumplimiento al contrato, lo cual

40 CONTARDO, op. cit., p.178.

41 Ídem.

42 DEL FAVERO, Octavio: Integración de la teoría de incumplimiento contractual por repudiación anticipada del contrato. Memoria de prueba para optar al grado de licenciado en ciencias jurídicas y sociales. Facultad de Derecho, Universidad de Chile. p. 43.

43 Ibíd. P. 46. 
le permite tomar ciertas decisiones frente a imposibilidad de ver satisfecho su interés ante este eventual incumplimiento. A su vez, esta exigencia sirve de límite frente a un posible ejercicio abusivo de la resolución en forma anticipada. No estamos frente a cualquier manifestación de voluntad por parte del deudor expresada conforme a sus dichos o conductas, sino, que se refiere a situaciones que traen como consecuencia una imposibilidad absoluta de ejecución del contrato en el plazo convenido, que generan en el acreedor la convicción de insatisfacción de su interés, el cual traerá aparejado su decisión de resolver el contrato y desvincularse de una relación obligacional que no traerá frutos.

La forma en que nuestro Código Civil trata al contrato válidamente celebrado y dentro del contexto de igualdad y libertad entre las partes, supone que existe una fuerte vinculación entre ellas una vez que han contratado, donde lo que se espera de cada una es que respeten la palabra que han empeñado y den cumplimiento a sus respectivas obligaciones tal cual como las han contraído, toda vez que el contrato es considerado una ley al regular la conducta de los contratantes, tiene fuerza obligatoria de ley respecto de ellos. De manera tal, que conforme a la importancia que nuestro Código Civil otorga a la autonomía privada y que frente a una manifestación clara de voluntad de una entidad tal, que permita al acreedor prever el incumplimiento futuro, no se vislumbran razones para no considerarlo como un incumplimiento del contrato, no respecto de la obligación misma que, a pesar de todo, se encuentra aún pendiente, si no al deber de ejecutar los contratos de buena fe y de respetar la palabra empeñada ${ }^{44}$, protegiendo la expectativa de cumplimiento que el acreedor mantiene desde el momento mismo de la celebración del contrato.

Juan Ignacio Contardo ${ }^{45}$ se refiere a esta situación, frente a la falta de regulación de la misma en los artículos 1826 del Código Civil y 147 del Código de Comercio, señalando que efectivamente una notificación expresa del deudor a acreedor indicando que no cumplirá con el pago del precio puede representar un justo temor de que efectivamente el incumplimiento del contrato se va a producir. Según el autor, esto puede interpretarse como que con dicha notificación el deudor renuncia al plazo, no para cumplir sino

44 A propósito del respeto a la palabra empeñada por los contratantes que libremente manifiestan su voluntad de obligarse y de determinar el contenido del contrato: López Santa María, Jorge. Los Contratos. Parte General”. Editorial Jurídica de Chile, Santiago, Tercera Edición, 2003. p. 198. 
para resolver el contrato. Junto con lo anterior, además se hace cargo de la posibilidad de que el deudor cambie de parecer, considerando, como se señaló más arriba, que la obligación se encuentra aún pendiente, indicando que al deudor se le podría aplicar la teoría de los actos propios, a fin de evitar que se contraríe su conducta anterior; asegurando el acreedor, que la resolución efectivamente surtirá efectos y podrá desvincularse del contrato.

c) Pérdida de la confianza.

Tal como señalamos anteriormente, la doctrina se encuentra conteste en orden a que la resolución del contrato procederá en la medida en que exista un incumplimiento que revista el carácter de esencial, toda vez que debe existir una correcta ponderación entre este remedio contractual y el principio de conservación de los actos. Sin embargo, no existe consenso en orden a cuándo este incumplimiento es esencial. Sin perjuicio de lo anterior, y tal como lo señala el profesor Vidal ${ }^{46}$, la infracción apta para que se proceda a la resolución es el incumplimiento esencial que comprende tres tipos de incumplimiento:

a) Aquellos incumplimientos que privan sustancialmente al acreedor de lo que tenía derecho a esperar en virtud del contrato, siempre que tal resultado hubiese sido previsible para el deudor al tiempo del contrato.

b) Cuando las partes así lo hubieren estipulado específica y claramente.

c) Aquellos incumplimientos dolosos, deliberados o con culpa grave y en todo caso en que se concluya inequívocamente que el acreedor no tiene razones para confiar en el cumplimiento posterior del deudor.

Nos detenemos en el último supuesto, toda vez que nos permite configurar la hipótesis en que las partes podrían eventualmente ejercer una acción de resolución anticipada del contrato, según lo anterior, lo enfocaremos respecto de la pérdida de confianza en el futuro cumplimiento de la obligación que podría sufrir tanto el acreedor como el deudor de la obligación cuyo cumplimiento aún se encuentra pendiente, conforme pasaremos a analizar.

Es posible que, en la ejecución de un contrato, se produzcan comportamientos dolosos ya sea deliberadamente o cometidos con culpa

46 VIDAL, op. cit., p. 253. 
grave, que permitan concluir de manera inequívoca por las partes, que se ha perdido la confianza en la ejecución futura o posterior de la obligación de la contraria. En estos casos, según señala Claudia Mejías, no resulta razonable exigir a la parte afectada, que mantenga la confianza en que la contraria ejecutará la prestación en los términos en que esta fue pactada, facultándosele para que se le ponga término ${ }^{47}$.

Como vimos en capítulos anteriores, en la actualidad, el incumplimiento de las obligaciones contractuales para efectos de ejercicio de la facultad resolutoria, es considerado objetivamente, a diferencia de lo que ocurre en la situación objeto del presente análisis, conforme a la cual, la gravedad del incumplimiento es subjetiva y está determinada por la conducta del deudor, que se opone a la buena fe objetiva consagrada en el artículo 1546 del Código Civil ${ }^{48}$, toda vez que se vulnera el acuerdo celebrado por las partes y a la obligación de mantener una conducta que asegure a la contraparte el cumplimiento de su cometido, tal cual como versa en el contrato ${ }^{49}$. Cabe hacer la precisión de que esta conducta que supone incumplimiento esencial por parte del deudor, incluye aquellas actuaciones que denotan tanto la intención clara de causar daño al acreedor, así como también aquellas que son ejecutadas sin tomar en consideración los intereses de la contraparte, es decir actuando con máxima negligencia respecto de ellos $^{50}$. En el mismo orden de pronuncia la profesora Pamela Prado, al referirse a este rol del dolo en la convención, señalando que es la concepción más adecuada. Junto con lo anterior, la autora agrega que, en este sentido, el dolo debe ser apreciado in concreto, así como también resulta fundamental la acreditación del mismo en la conducta del deudor a fin de que el juzgador pueda formarse tal convicción o bien, inferir inequívocamente su comportamiento de aquella conclusión. ${ }^{51}$

47 MEJÍAS, op. cit., p. 265.

48 VIDAL, op. cit.

49 DUCCI, Carlos: Derecho Civil Parte General. Cuarta Edición. Editorial Jurídica de Chile, Santiago, 2005. p. 29. Específicamente el autor señala que respecto de esta conducta que se espera del deudor, la buena fe "consiste en la fidelidad a un acuerdo concluido o, dentro del circulo obligatorio, observar la conducta necesaria para que se cumpla en forma comprometida la expectativa ajena".

50 ABELIUK, René: Las Obligaciones. Tomo II. Editorial Jurídica de Chile. Tercera Edición, Santiago. p. 681.

51 PRADO, Pamela: "La resolución anticipada del contrato: reanudando el debate en torno al incumplimiento doloso". En: Estudios de Derecho Civil XIII. Jornadas Nacionales de Derecho Civil Pucón 2017. Editorial Thomson Reuters, Santiago, 2018. pp. 689-705. 
Estos incumplimientos dolosos que se pueden producir a lo largo del íter contractual, permiten llegar a la conclusión de que se trata de un incumplimiento de carácter esencial, que perfectamente puede producirse antes de que el plazo se encuentre vencido, y que darían lugar a solicitar la resolución anticipada del contrato. La consideración de este tipo de conductas como incumplimientos de carácter esencial, ha sido ampliamente reconocida por el derecho uniforme. Si bien la Convención de Viena sobre Derecho de los Contratos, consiste en la base conforme a la cual los otros cuerpos normativos enfocan el incumplimiento esencial, y lo complementan con las otras categorías del mismo, dentro de las cuales se encuentran los incumplimientos malintencionados o dolosos. Ejemplo de lo anterior es lo establecido en los PECL los cuales amplían ${ }^{52}$ el concepto de incumplimiento esencial, incluyendo en él al incumplimiento doloso e intencional, pero manteniendo la base de la CISG, disponiendo en su artículo 8:103 que el incumplimiento es esencial, "letra c) o cuando el incumplimiento sea intencionado y de motivos a la parte perjudicada para entender que ya no podrá contar en el futuro con el cumplimiento de la otra parte". Por su parte, los Principios de UNIDROIT, siguen la línea anterior, y en su artículo 7.3.1 (2) señalan como incumplimiento esencial: "(c) el incumplimiento es intencional o imprudente; (d) el incumplimiento le da a la parte perjudicada una razón para creer que no puede confiar en el desempeño futuro de la otra parte. A su turno, el MCR, que en la letra b) de su artículo III: 3:502, (2), señala que el incumplimiento es esencial cuando: "(b) es intencional o imprudente y le da al acreedor razones para creer que no se puede confiar en el desempeño futuro del deudor". A nivel regional, el Borrador de los PLDC en la letra b) de su artículo 87, señala que "Se entiende que el incumplimiento es esencial cuando es doloso y letra c) La conducta del deudor incumplidor hace perder razonablemente al acreedor la confianza en el cumplimiento posterior del contrato".

Si bien, hemos analizado la posibilidad de configurar un incumplimiento esencial por parte del deudor de la obligación que se encuentra pendiente, toda vez que a lo largo del íter contractual realiza conductas que deliberadamente son maliciosas o bien fueron ejecutadas con negligencia, haciendo posible que acreedor ejerza la acción resolutoria, incluso pensamos, con anterioridad al vencimiento del plazo, toda vez que la conducta del deudor atenta contra el principio de buena fe negocial. Así las

52 VAQUER ALOY, Antoni: "El soft Law europeo en la jurisprudencia española: Doce casos”. En: Ars Iuris Salmanticensis. Estudios, Vol. 1, 93-115. Junio 2013. 
cosas, creemos que este tipo de conductas de carácter malicioso, así como pueden ser ejercidas por el deudor de la obligación, perfectamente también pueden provenir de parte del acreedor, por ejemplo, en todos aquellos casos en que se exceda por su parte el ejercicio del derecho de opción frente a un eventual incumplimiento contractual, generándose abuso del mismo.

En general, la doctrina nacional no se ha referido al abuso del derecho de opción del acreedor entre los diversos remedios contractuales frente al incumplimiento del deudor, sin embargo Patricia López nos entrega un concepto al respecto, que permite ilustrar la idea: "Existirá abuso del derecho en aquellos casos en que el acreedor escoge un remedio por incumplimiento, no con la finalidad de satisfacer su interés contractual, sino con el propósito de causar perjuicio al deudor o cuando sin desear tal perjuicio lo acepta, existiendo una extrema desproporción entre el interés del titular y el efecto negativo que produce en otra persona el ejercicio del Derecho" 53 .

Siguiendo la postura de la profesora López, existen tres presupuestos que permiten configurar la figura del abuso del derecho de opción por parte del acreedor insatisfecho: a) ejercicio del derecho de opción del acreedor, b) intención de lesionar el interés contractual del deudor y c) lesión del interés contractual del deudor.

Dentro de las posibilidades en las cuales se pueden producir situaciones de abuso del derecho de opción nos encontramos por ejemplo aquellas situaciones en las cuales el acreedor demande el deudor la ejecución de una prestación que si bien no es imposible, se ha tornado sumamente gravosa o costosa, o bien en casos en que demande resolución del contrato frente a un incumplimiento que no reviste el carácter de esencial, o bien en casos en que el legislador no faculte al acreedor para solicitar la indemnización de perjuicios o no exista límite alguno para demandar la pretensión de cumplimiento específico y este sea aun posible e idóneo para satisfacer su interés originario o específico. Con independencia del caso de abuso del derecho de opción por parte del acreedor, nos quedamos para efectos del presente trabajo con el hecho de que en cada hipótesis de abuso del derecho existe intención de lesionar el interés contractual del deudor, el segundo presupuesto de la figura en comento resulta determinante para efectos del presente estudio, toda vez que al ser un acto contrario a la

53 LÓPEZ, Patricia: "El abuso del derecho de opción del acreedor y su importancia en la construcción de un sistema equilibrado de remedios por incumplimiento contractual". En: Revista Chilena de Derecho Privado, No 19, 2012. Pp.13-62. 
buena fe negocial ${ }^{54}$, supone, tal como vimos más arriba, una conducta que perfectamente puede hacer perder la confianza del deudor, en su acreedor, respecto del cumplimiento del contrato. Si consideramos que estas situaciones, pueden producirse en aquellos casos en los cuales las obligaciones de encuentran pendientes porque el plazo de cumplimiento aún no se cumple, y el acreedor realiza conductas que suponen abuso de su derecho de opción de alguno de los remedios contractuales frente a un "supuesto" incumplimiento del deudor o frente a alguna conducta del deudor que él considere como incumplimiento y sin embargo la obligación del deudor aún se encuentra pendiente, el deudor puede perder la confianza en que su acreedor cumplirá con su parte del contrato, toda vez que ha actuado de mala fe, se ha apartado del ambiente de confianza que debe rodear a las partes desde que comienzan las tratativas preliminares, hasta la completa ejecución del contrato. Es probable, es que si el deudor se enfrenta a alguna de estas situaciones, responda la demanda de su acreedor alegando como excepción el abuso del derecho de opción de su contraparte ${ }^{55}$ y además creemos que en la hipótesis de pérdida de confianza de su parte en el cumplimiento del contrato por parte del acreedor, toda vez que actuó en forma maliciosa con la clara ${ }^{56}$ intención de provocar un daño en el legítimo interés contractual del deudor, el cual consiste en liberarse del cumplimiento de la obligación y no ver agravada su posición en el vínculo obligatorio como consecuencia del incumplimiento ${ }^{57}$; podría perfectamente demandar reconvencionalmente la resolución del contrato, justificando su acción, en el incumplimiento esencial anticipado de parte de su acreedor, toda vez que el mismo desplegó una conducta que atenta contra la buena fe negocial, haciendo perder la confianza en el comportamiento del acreedor respecto del futuro cumplimiento del contrato, configurando entonces, un

54 Ibídem. BARROS, Enrique: "Límites de los derechos subjetivos privados. Introducción a la Doctrina del Abuso de Derecho". En: Derecho y Humanidades, N7, 1999 doi:10.5354/0719-2517.2012.25764

55 LÓPEZ, op. cit. Según la autora, el juez en una situación como esta, tendría la opción de denegar al acreedor el remedio contractual escogido, pero no tendría facultades para imponer al acreedor un remedio contractual diverso, toda vez que excedería el objeto de la demanda e infringiría del principio dispositivo y el principio de congruencia procesal.

56 Es claro que al momento de formular la hipótesis en comento, asumimos que el deudor, ha logrado acreditar que efectivamente el acreedor actuó dolosamente o bien el mismo no logró desacreditar la imputación de negligencia que el deudor claramente debió haberle hecho a su actuar, al momento de contrademandar, al realizar el ejercicio abusivo de la acción que solicitaba el remedio contractual escogido.

57 LÓPEZ, op. cit.. 
incumplimiento de carácter esencial del contrato, en forma anticipada a la exigibilidad de las obligaciones que emanan del mismo.

\section{d) Autonomía privada.}

Toda vez que nos encontramos en el ámbito privado, las partes son libres para determinar el contenido del contrato, teniendo como limite la moral, las buenas costumbres y el orden público. Partiendo de lo anterior, el presente apartado tiene por objeto analizar aquellas situaciones en las cuales las partes pueden incluir dentro de las cláusulas contractuales, alguna dedicada a la regulación de aquella situación en la cual se prevea por parte de cualquiera de ellas, un incumplimiento anticipado de la obligación de la otra, es decir, encontrándose pendiente el plazo.

Se ha propuesto ${ }^{58}$ que las partes incorporen la posibilidad de resolver anticipadamente el contrato cuando se prevé el incumplimiento por parte del deudor, mediante la figura del pacto comisorio.

El pacto comisorio se encuentra regulado en nuestro Código Civil a propósito de la compraventa en los artículos 1877 y siguientes y con razón del incumplimiento de la obligación de pagar el precio, sin embargo, su aplicación es de carácter general ${ }^{59}$, es decir: no se encuentra circunscrito únicamente a ser aplicado respecto de un contrato de compraventa, así como tampoco respecto de la obligación de pagar el precio, sino que es perfectamente posible, toda vez que nos encontramos dentro del ámbito de la libertad contractual, que las partes fijen cualquier hecho posible y lícito como condición resolutoria, respecto de la cual, no existe razón para excluir al incumplimiento anticipado de la obligación. Lo que se propone por parte de Del Favero, "es que las partes acuerden que se otorgue el derecho de exigir el cumplimiento forzado o resolución del contrato con indemnización de daños, en el caso de que, con anterioridad a la exigibilidad de la obligación, fuese evidente que la contraparte no quiere o no puede cumplir con lo prometido. De esta forma, la circunstancia bajo la cual opera el Pacto Comisorio no será el incumplimiento actual de la obligación principal, si no que el evento de un incumplimiento del deber de no repudiar el contrato o de conservar la habilidad para cumplirlo. Las partes deben ser explicitas y claras en la determinación de qué

58 DEL FAVERO, op. cit., p. 51. CARDENAS, Hugo. REVECO, Ricardo, op.cit..

59 ABELIUK, op. cit., p. 423. 
incumplimiento dará lugar a la resolución del contrato" ${ }^{60}$. Lo que destaca el autor, es específicamente que respecto de esta cláusula, las partes deben señalar en forma expresa que están obligadas a no repudiar el contrato y que se comprometen a conservar la habilidad física y moral para dar cumplimiento a sus respectivos cometidos. Incluso posteriormente el autor señala que se podría prescindir de la intervención judicial mediante el acuerdo de un pacto comisorio calificado. Cualquiera sea la cláusula que incorporen las partes, se recomienda utilizar un mecanismo que incluya la notificación por parte del acreedor al deudor de su decisión de resolver el contrato ya que ofrece la posibilidad de que el acreedor renuncie a la resolución e insista en el cumplimiento específico, de modo tal de permitirle optar al remedio que mejor satisfaga sus necesidades una vez que se el incumplimiento se produce.

Si bien es cierto que nuestro ordenamiento jurídico, tal como vimos más arriba, regula el pacto comisorio respecto del incumplimiento de la obligación de pagar el precio, en razón de la filosofía ${ }^{61}$ que envuelve a las normas de orden privado, no existiría razón para no permitir que las partes regulen la situación en comento a través de esta institución, toda vez que exista voluntad seria de obligarse. Como en el caso en concreto no existe un interés de la colectividad en la aplicación de la norma, las partes perfectamente mediante la autonomía privada pueden utilizarla para regular esta situación.

La doctrina propone clausulas modelo, que eventualmente las partes podrían incluir en sus contratos, con la finalidad de regular aquella situación en la que podría preverse un incumplimiento en forma anticipada a la llegada del plazo, por ejemplo:

1) " $\mathrm{Si}$, antes de la fecha de inicio del contrato, el arrendatario notifica al propietario o demuestra inequívocamente una intención de incumplir y repudiar este contrato o incumple cualquier obligación de inquilino

60 DEL FAVERO, op. cit., p. 124.

61 ALESSANDRI R. Arturo, SOMARRIVA, Manuel, VODANOVIC, Antonio: Tratado de Derecho Civil. Partes Preliminar y General". Tomo Primero. Editorial Jurídica de Chile, Santiago. p. 30. Los autores textualmente indican: "En la norma de orden público hay un interés social en que la regulación de los casos que trata sea una sola para todos los individuos, la que dicha norma determina. Distinta es la filosofía de la norma de orden privado: la regulación prescrita se estima beneficiosa para la generalidad de los particulares, pero sin desconocer que éstos, en sus situaciones o relaciones concretas, puedan tener por conveniente otra que ellos mismos se den, y como no aparece comprometido ningún interés de la colectividad, dicha norma permite que se la descarte." 
en virtud del presente, el propietario puede, a su discreción, considerar dicho repudio anticipado como incumplimiento de este contrato de arrendamiento. Además de cualquier otro recurso disponible en virtud del presente, en derecho, el propietario podrá terminar el contrato en forma unilateral y anticipada; y, si corresponde, reclamar daños y perjuicios al arrendatario." 62

En los cuatro grupos de casos revisados anteriormente, conforme a las normas de nuestro ordenamiento jurídico, sería posible solicitar la resolución de los contratos afectados, en forma anticipada, en orden a que todas las hipótesis analizadas, podrían configurarse antes de que la obligación se hiciera exigible. Además de lo anterior, en cada uno de los casos revisados, es posible observar que es posible que se cumplan los requisitos de procedencia de la resolución por incumplimiento anticipado que ya revisamos anteriormente, esto es: que el incumplimiento previsible se asimile a un incumplimiento actual para resolver el contrato, el incumplimiento que se prevé tenga el carácter de esencial a fin de que permita dar lugar a la resolución del contrato y no debe haber lugar a ninguna duda respecto a que el deudor no ejecutará su prestación en tiempo $\mathrm{y}$ forma o bien que aparezca como un hecho muy probable.

Es cierto que la doctrina de la resolución del contrato por incumplimiento anticipado del mismo, no está regulada en nuestro ordenamiento jurídico, sin embargo, creemos que los lineamientos fundamentales de la teoría, no se encuentran en contradicción con los principios generales de nuestra legislación, como quedó de manifiesto con el análisis de los casos anteriores, de manera tal, que es una doctrina que podría ser aplicada en nuestro país, a situaciones específicas de derecho privado, en las cuales podamos observar que sus requisitos se encuentran presentes, teniendo en consideración la doble excepcionalidad de la figura. En todos los casos, nos encontramos en presencia de situaciones en las cuales es posible prever de antemano por parte del acreedor, y en forma fehaciente, que el deudor no va a cumplir con su obligación al momento de llegar el plazo previsto por ambas partes al celebrar el contrato y que si bien nuestro ordenamiento jurídico interno, no contempla la figura de la resolución por incumplimiento anticipado del contrato, no prohíbe hacerlo, toda vez que los fundamentos de la doctrina no se contradicen con nuestro cuerpo normativo.

62 CARDENAS, Hugo. REVECO, Ricardo. op. cit., p. 265. 
e) Imposibilidad sobrevenida.

Respecto de las situaciones que analizaremos a continuación, nos ubicamos en el contexto en que surja alguna causal que torne en imposible el cumplimiento de la obligación, aun encontrándose pendiente el plazo para exigir el cumplimiento de la misma, y que por tanto, en razón de esto, el acreedor tome conocimiento (cualquiera sea la vía) anticipadamente a la exigibilidad de la obligación, de que el deudor no cumplirá con su cometido atendido a que ha tenido lugar alguna circunstancia de imposibilidad. Como primera cosa, es necesario aclarar que si bien en casos en que surja alguna causal de imposibilidad de cumplimiento de la obligación, ya sea imputable o inimputable al deudor, compartimos la idea de que nos encontramos en situaciones que no participan de la naturaleza jurídica de un incumplimiento contractual propiamente dicho ${ }^{63}$, sin embargo para efectos de este trabajo, las analizaremos bajo ese alero toda vez que concordamos con la postura del profesor Vidal, en el sentido de considerar al incumplimiento como un hecho amplio establecido en base a la simple constatación de la falta de coincidencia entre el objeto ideal y el objeto real del contrato por parte del deudor, inclusive en aquellos casos en que dicha desviación haya tenido como causa un caso fortuito ${ }^{64}$.

Conforme a la imposibilidad sobrevenida de cumplimiento de la obligación, nuestro ordenamiento jurídico se refiere a la misma respecto del caso de pérdida de la cosa debida en el contexto de las obligaciones de dar, en el artículo 1550 del Código Civil señalando que el riesgo del cuerpo cierto cuya especie se deba, es siempre de cargo del acreedor, lo cual se traduce en que en caso de que se produzca la situación contenida en

63 CASTILLA, Margarita: La imposibilidad de cumplir los contratos. Editorial Dykinson, S.L., Madrid, 2001. pp. 222 ss. Distingue la autora entre imposibilidad sobrevenida imputable e inimputable. Respecto de la primera señala que al igual que el incumplimiento es un hecho generador de responsabilidad patrimonial que se distingue de este, en el sentido en que su envergadura es tal, que no solo implica que la obligación no se ha cumplido, sino que no podrá ser cumplida jamás en los términos en que inicialmente se pactó. Respecto de la segunda, indica que se adjudica una naturaleza jurídica distinta tanto del incumplimiento como de la imposibilidad sobrevenida imputable, toda vez que no corresponde a un hecho generador de responsabilidad patrimonial, sino a un modo de extinguir las obligaciones, lo cual hace que difieran las consecuencias jurídicas de ambas situaciones.

64 VIDAL, op. cit., p. 233. En este mismo sentido se manifiesta Margarita Castilla Barea (Óp. Cit. Pág. 465) en orden a señalar que "la imposibilidad sobrevenida puede conceptuarse como un "incumplimiento" siempre que este se entienda desnudo de juicios de reprochabilidad, es decir, siempre que adoptemos el significado que lo concibe como la simple transgresión, voluntaria o no, del programa prestacional pactado". 
la norma, el deudor cuya prestación se ha hecho imposible podrá demandar el cumplimiento de lo que corresponda a su acreedor o retener lo que éste ya haya dado o pagado sin que este último pueda exigir repetición, pedir la resolución del contrato u oponer excepción de contrato no cumplido ${ }^{65}$. No es del caso adentrarnos en profundidad en el tema de la falta de justificación de radicar el riesgo en el acreedor ${ }^{66}$, concordamos con la doctrina que se inclina por considerar que es justo que el deudor quede liberado del cumplimiento de su obligación frente a una situación de caso fortuito, pero que sin embargo, no es equitativo que la contraria, siga obligada a cumplir con su prestación, en esta hipótesis en que no recibirá nada a cambio. Frente a esta situación, de inequidad, conforme a la cual el acreedor debe soportar el riesgo del caso fortuito, consideramos que a pesar de lo señalado en el artículo 1550 del Código Civil, existe la posibilidad (siempre encontrándonos en el ámbito de la supletoriedad de norma de la voluntad de las partes, caso en el cual ellas perfectamente podrían haber previsto esta situación y regularla en la convención), con fundamento jurídico, de que el acreedor se libere del cumplimiento de esta obligación, que ahora es parte de un contrato que no le resultará útil, o al menos no servirá para satisfacer las necesidades que tenía en miras de satisfacer al momento de celebrar el contrato. La doctrina ${ }^{67}$ ha señalado que existe una falta de equidad y justificación en la solución contenida en el artículo 1550 del Código Civil lo cual sumado a la gran cantidad de excepciones que tiene la regla en el mismo cuerpo legal, les permite sostener que dicha norma tiene el carácter de excepcional, a pesar de su tajante redacción al utilizar la voz "siempre" y de su ubicación en el título de los efectos de la obligación en general, de manera tal que la regla general en nuestro ordenamiento jurídico es que el riesgo es de cargo del deudor cuya prestación de ha hecho imposible y que el hecho de que el riesgo sea soportado por el acreedor, solo se aplica en aquellos casos en que la imposibilidad inimputable se produzca únicamente en caso de pérdida de cosa debida ${ }^{68}$ y solo respecto de las obligaciones

65 ABELIUK, op. cit., pp. 988 ss.

66 Ibíd.

67 ALESSANDRI Y OTROS, op. cit.; FUEYO, op.cit.; ABELIUK, op. cit.

68 ABELIUK, op. cit. 
de dar específicas ${ }^{69}$. Según el profesor Fueyo ${ }^{70}$, la posibilidad de resolver el contrato bilateral frente a una situación de imposibilidad sobrevenida inimputable, radica en la relación de reciprocidad de las prestaciones propia del contrato bilateral, toda vez que frente a una imposibilidad inimputable de cumplir con la obligación original producirá el efecto de extinción de la misma seguida de la resolución del contrato y además, como respecto de todo ejercicio del remedio resolutorio, permite al contratante cumplidor desligarse del contrato que dejó de ser idóneo para satisfacer el fin que tuvo al momento de contratar y así poder dentro del plazo más breve posible, poder celebrar una operación de reemplazo. En términos generales, el autor sostiene ${ }^{71}$ que "el fundamento de la resolución por imposibilidad sobreviniente inimputable no hemos de entenderlo diferente que en el caso de resolución por incumplimiento imputable", por otra parte, señala que los efectos del ejercicio del remedio "no son otros que los de volver las cosas a su punto de partida, con las prestaciones mutuas que el caso determine". El autor sostiene que tres serían los requisitos para que el ejercicio de la acción resolutoria en este sentido sea posible ${ }^{72}$ : A) que se trate de una imposibilidad sobreviniente de la prestación de carácter definitiva, descartándose cualquiera remota posibilidad de cumplimiento futuro en caso de una imposibilidad temporal. B) Falta de culpa del deudor, lo cual es fundamental para que se produzca la extinción de la obligación del deudor seguida de la resolución del contrato y C) Que por las diversas razones que contempla nuestro ordenamiento jurídico, el deudor no sea responsable del caso fortuito. Discrepamos respecto del segundo requisito, conforme pasamos a indicar a continuación:

Ahora bien, sin perjuicio de lo señalado en el párrafo anterior, somos de la idea de que el ejercicio del remedio resolutorio por imposibilidad sobreviniente inimputable, es perfectamente aplicable respecto de casos en que la imposibilidad es imputable al deudor, toda vez que, tal como dijéramos más arriba, al producirse esta imposibilidad de cumplir, existe

69 FUEYO, op. cit. No en las obligaciones genéricas, porque en principio el género no perece de manera tal que no se configura la imposibilidad de cumplimiento. Tampoco en las obligaciones de hacer o no hacer, toda vez que no está reglamentada esta situación por el Código Civil y según el profesor René Abeliuk (Ídem. Pág. 993), frente a falta de disposición expresa debe aplicarse la solución que encuentre su fundamento en la equidad, es decir, poner el riesgo por cuenta del deudor cuya prestación se ha hecho imposible, entre otros argumentos.

70 FUEYO, op. cit.p. 333.

71 Ibíd, pp 331 ss.

72 Ibíd. 
una disconformidad entre el objeto ideal y el objeto real del contrato, de manera tal que se justificaría la resolución. Así las cosas, es necesario hacer la siguiente distinción a modo explicativo: por una parte, nos encontramos frente a hipótesis de imposibilidad sobreviniente por pérdida de la cosa debida en caso de obligaciones de dar específicas, casos en los cuales conforme a lo señalado en los artículos 1550 y 1672 del Código Civil, en caso de inimputabilidad la obligación del deudor se extingue, justificando la resolución del contrato; y en caso de que la perdida sea imputable, la obligación subsiste, transformada en el deber de reparar los daños conforme a las reglas generales, no dando lugar a la resolución, idea recogida por el profesor Fueyo en su explicación. Por otra parte, frente a una eventual hipótesis de imposibilidad sobreviniente ya sea imputable o inimputable de cumplir cualesquiera de otro tipo de obligación distinta a la de entregar una especie o cuerpo cierto determinada (por ejemplo, el caso de un músico al cual le resulta imposible asistir a un concierto privado contratado por su acreedor, por haber sido víctima de un accidente automovilístico el cual le obliga a realizar reposo absoluto por un plazo superior a aquel fijado como fecha para el concierto), toda vez que nuestro código civil no se pronuncia al respecto, somos de la idea de que nos encontramos frente a un incumplimiento de la obligación, ya que como señaláramos más arriba, existe una discrepancia entre el objeto ideal y el objeto real del contrato, es decir, si esta discrepancia es de carácter esencial, el supuesto básico de ejercicio del remedio resolutorio está presente. ${ }^{73}$ La diferencia entre ambas situaciones se verá reflejada en el hecho de que el remedio resolutorio venga acompañado de consecuencias indemnizatorias o no, dependiendo de si es posible imputar a la conducta del deudor la consecuencia de la imposibilidad de cumplir. Respecto de todas estas situaciones en que el deudor se enfrente a una causal de imposibilidad de cumplimiento de la obligación, ya sea imputable o no, será posible solicitar la resolución del contrato, por las razones que se señalaron. Inclusive en el caso en la perdida de la cosa debida se produzca por razones imputables a la voluntad del deudor, haciendo subsistir la obligación transformada en aquella de indemnizar perjuicios, toda vez que nos podríamos encontrar en el caso en que substituir la cosa debida por dinero, al acreedor no le satisfaga el más mínimo interés y prefiera desligarse de la relación contractual a fin de celebrar otra en el corto plazo y que conforme a las razones económicas, de

73 Nos remitimos en este punto a lo ya dicho anteriormente relativo al incumplimiento que exige el artículo 1489 del Código Civil para la procedencia del remedio. En este mismo sentido se pronuncia CASTILLA BAREA, op. cit., p. 469. 
justicia contractual y de buena fe contractual que se analizarán en detalle al finalizar el presente capítulo, debiera tener la posibilidad de ejercer este remedio satisfactoriamente.

En cuanto a lo que a este trabajo respecta, debemos decir que la situación anteriormente descrita perfectamente puede producirse en el contexto de un contrato bilateral en que la imposibilidad de cumplimiento, ya sea imputable o no, sea un hecho cierto antes del vencimiento del plazo. Es perfectamente posible que esto ocurra y que el acreedor tome conocimiento de esta situación antes de que el plazo se cumpla. Ateniéndonos a los requisitos señalados por el profesor Fueyo, el primero de ellos y con el cual concordamos señala expresamente: “A) que se trate de una imposibilidad sobreviniente de la prestación de carácter definitiva, descartándose cualquiera remota posibilidad de cumplimiento futuro en caso de una imposibilidad temporal". Nos encontramos frente a una situación que no tiene posibilidad de ser revertida en el futuro, de manera tal que logrando acreditar el acreedor que la imposibilidad es definitiva, lograría probar que al momento de producirse el vencimiento del plazo, la obligación no se va a cumplir, debiendo tener la posibilidad de solicitar entonces la resolución anticipada del contrato, toda vez que se cumplirían los requisitos de procedencia de este remedio particular, conforme al detalle de los mismos señalados anteriormente.

\section{CONCLUSIONES.}

1.- En virtud del carácter utilitario que se reconoce hoy en día al contrato y a la naturaleza fungible de las obligaciones que constituyen predominantemente el tráfico jurídico actual, no resulta provechoso para los intereses de las partes contratantes mantenerse vinculadas a un contrato, respecto del cual, tienen conocimiento con antelación a la exigibilidad del mismo, que no les reportará beneficio económico alguno, volviéndose un instrumento que no cumple con su cometido de satisfacer los intereses que se tuvieron en miras al momento de contratar.

2.- Conforme al tratamiento otorgado al remedio resolutorio por parte del nuevo derecho de la contratación, en su función económica, permite al contratante insatisfecho recuperar los recursos utilizados en el contrato para darles otro destino. El efecto liberatorio de la resolución, sumado al carácter instrumental del contrato, hacen que dentro del abanico de remedios a los que puede recurrir frente al incumplimiento contractual, esta sea, para el acreedor, una opción rápida, eficaz y conveniente de 
liberarse del vínculo contractual y volver al mercado a buscar una mejor opción de satisfacción de intereses. Lo anterior cobra especial relevancia atendido a que las obligaciones que forman parte del tráfico jurídico actual son principalmente de objeto fungible, de manera tal que posibilidades de satisfacción de las mismas existen tantas, como disponibles en el mercado.

3.- Arribamos a la idea de que los elementos rectores de la figura de resolución por incumplimiento anticipado del contrato, son al menos tres: a) se asimila el incumplimiento previsible al incumplimiento "actual" para resolver el contrato, b) el incumplimiento que se prevé debe ser esencial y c) no debe haber lugar a ninguna duda respecto de que el deudor no ejecutará su prestación en tiempo y forma o bien, que aparezca con una alta probabilidad de no ocurrir.

4.- Participamos de la postura que sostiene que la constitución en mora es un requisito necesario únicamente para el ejercicio de la acción indemnizatoria, más no para la resolución en cuanto remedio contractual. Al no ser necesario el ejercicio conjunto del remedio resolutorio con el indemnizatorio, no es requisito en los casos analizados en el presente trabajo, que el deudor se encuentre constituido en mora para que el acreedor ejerza la acción resolutoria; y no va a ocurrir, toda vez que no existe en estos casos imputabilidad de los daños, de manera que solo se ejercerá el remedio resolutorio al cumplirse con los requisitos del mismo señalados en el numeral anterior, generando como única consecuencia la desvinculación de las partes con el contrato que las ligaba, quedando liberadas de sus obligaciones, a fin de poder celebrar libremente operaciones de reemplazo.

5.- En general, la hipótesis analizada consistió en aquella en que el acreedor de una obligación sujeta a plazo, toma conocimiento fehacientemente, encontrándose el plazo pendiente, de que una vez llegado el mismo, el deudor no ejecutará su cometido. En cada uno de los casos analizados, regulados por nuestro ordenamiento jurídico, se cumple esa premisa. Tal como se explica en detalle, en cada uno de estos casos, sería posible ejercer la acción resolutoria en forma previa al vencimiento del plazo que hace exigible la obligación, atendida la excepcional situación en la que se encuentran las partes y conforme a una interpretación armónica de las normas que regulan cada de una de las situaciones planteadas a la luz de las directrices del nuevo derecho de la contratación. 


\section{BIBLIOGRAFIA.}

ABELIUK, René: Las Obligaciones. Tomo I. Editorial Jurídica de Chile. Santiago, Tercera Edición.

ABELIUK, René. "Las Obligaciones. Tomo II". Editorial Jurídica de Chile. Tercera Edición.

ALCALDE, Enrique:"Incumplimiento reciproco, resolución y cumplimiento de contrato bilateral". En: Revista Chilena de Derecho, Vol. 31, 2004.

ALESSANDRI R. Arturo, SOMARRIVA, Manuel, VODANOVIC, Antonio: Tratado de Derecho Civil. Partes Preliminar y General". Tomo Primero. Editorial Jurídica de Chile, Santiago.

BARROS, Enrique: "Límites de los derechos subjetivos privados. Introducción a la Doctrina del Abuso de Derecho". En: Derecho y Humanidades, (7)., 1999, doi:10.5354/0719-2517.2012.25764.

CARDENAS, Hugo. REVECO Urzúa, Ricardo. "Remedios contractuales. Clausulas, acciones y otros mecanismos de tutela del crédito". Editorial Thomson Reuters, Santiago, 2018.

CASTILLA, Margarita: La imposibilidad de cumplir los contratos. Editorial Dykinson, S.L., Madrid, 2001.

CONTARDO, Juan Ignacio. "La resolución por incumplimiento previsible y la suspensión del cumplimiento como medios de tutela anticipatoria del acreedor". En: Ian Henríquez Herrera (Coordinador): La Compraventa. Nuevas perspectivas doctrinarias. Editorial Thomson Reuters, Santiago, 2015.

CONTARDO, Juan Ignacio: Indemnización y resolución por incumplimiento. Editorial Legal Publishing Chile. Primera Edición, Santiago, 2015.

DEL FAVERO, Octavio: Integración de la teoría de incumplimiento contractual por repudiación anticipada del contrato. Memoria de prueba para optar al grado de licenciado en ciencias jurídicas y sociales. Facultad de Derecho, Universidad de Chile, 2013.

DUCCI, Carlos: Derecho Civil Parte General. Cuarta Edición. Editorial Jurídica de Chile, Santiago, 2005. 
FUEYO, Fernando. Cumplimiento e incumplimiento de las obligaciones. Editorial Jurídica de Chile, Santiago, 2015.

GALVÁN, José Antonio: “Conferencia Inaugural del II Congreso Chileno de Derecho privado". En: Revista de Derecho de la Universidad Católica de Valparaíso, XIV, 1998.

LÓPEZ, Patricia. "El abuso del derecho de opción del acreedor y su importancia en la construcción de un sistema equilibrado de remedios por incumplimiento contractual". En: Revista Chilena de Derecho Privado, No 19, 2012.

LÓPEZ, Jorge: Los Contratos. Parte General. Editorial Jurídica de Chile, Santiago, Tercera Edición, 2003.

MEJÍAS, Claudia: El incumplimiento resolutorio en el Código Civil. Editorial Legal Publishing Chile, Santiago, 2011.

MORALES, Antonio Manuel. La Modernización del Derecho de las Obligaciones. Editorial Thomson Civitas, Madrid, 2006.

PEÑA, Cristóbal: "La autonomía de la voluntad en el derecho comparado. Nuevos paradigmas de la contratación moderna". En: Revista de Derecho, No 32, 2014.

PEÑAILILLO, Daniel: "Algunas reformas a la resolución por incumplimiento". En: Revista de Derecho de la Universidad de Concepción № 231-232, Año LXXX, Enero-Junio, Julio Diciembre 2012

PEREZ GURREA, Rosana: "El incumplimiento esencial del contrato como categoría independiente del incumplimiento resolutorio en la Jurisprudencia del Tribunal Supremo". En: Revista Crítica de Derecho Inmobiliario, № 752.

PIZARRO, Carlos: "Contra el fatalismo del perjuicio a propósito del deber de mitigar el daño". En: Revista de Derecho de la Pontificia Universidad Católica de Valparaíso, XLI, 2013.

PRADO, Pamela: "La resolución anticipada del contrato: reanudando el debate en torno al incumplimiento doloso". En: Estudios de Derecho Civil XIII. Jornadas Nacionales de Derecho Civil Pucón 2017. Editorial Thomson Reuters. Santiago, 2018.

VAQUER ALOY, Antoni: "El soft Law europeo en la jurisprudencia española: Doce casos”. En: Ars Iuris Salmanticensis. Estudios, Vol. 1, 93-115. Junio 2013.

VIDAL, Álvaro. "La noción de incumplimiento esencial en el Código Civil". En: Revista de Derecho de la Pontificia Universidad Católica de Valparaíso, XXXII, primer semestre de 2009. 